
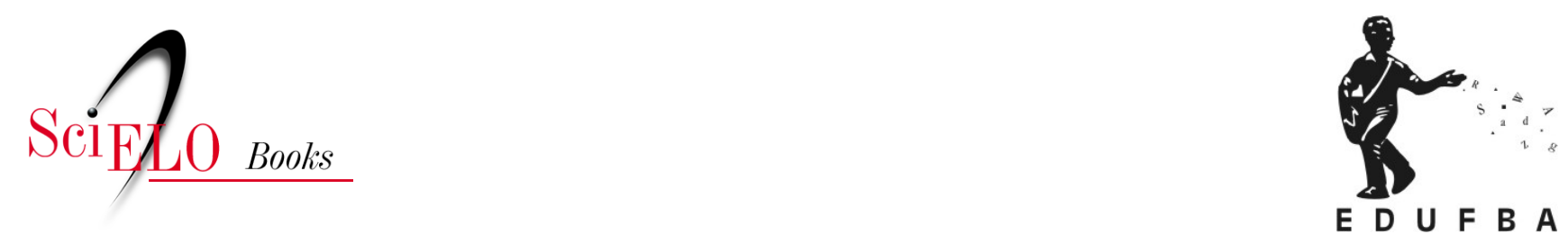

\title{
Poder psiquiátrico e transgeneridade: em torno da verdade diagnóstica
}

\author{
Beatriz Pagliarini Bagagli
}

\section{SciELO Books / SciELO Livros / SciELO Libros}

BAGAGLI, B.P. Poder psiquiátrico e transgeneridade: em torno da verdade diagnóstica. In:

MESSEDER, S., CASTRO, M.G., and MOUTINHO, L., orgs. Enlaçando sexualidades: uma tessitura interdisciplinar no reino das sexualidades e das relações de gênero [online]. Salvador: EDUFBA, 2016, pp. 235-248. ISBN: 978-85-232-1866-9. https://doi.org/10.7476/9788523218669.0013.

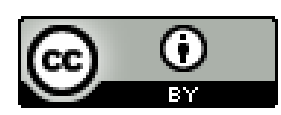

All the contents of this work, except where otherwise noted, is licensed under a Creative Commons Attribution $\underline{4.0 \text { International license. }}$

Todo o conteúdo deste trabalho, exceto quando houver ressalva, é publicado sob a licença Creative Commons Atribição 4.0. 


\section{Poder psiquiátrico e transgeneridade:}

\section{em torno da verdade diagnóstica}

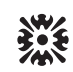

Beatriz Pagliarini Bagagli

Meu texto tenta reunir alguns pensamentos dispersos e iniciais acerca da questão dos processos de subjetivação que estou tentando traçar a partir de algumas leituras de Michel Foucault no que se refere à questão transgênera e psiquiátrica. Isto porque este autor em diversas partes de sua obra se questionou acerca da constituição da subjetividade a partir da própria existência de discursos que pretendem dizer as verdades do sujeito.

Procuro então pensar sobre as práticas que o sujeito tem que estabelecer em relação a ele mesmo no reconhecimento de seu próprio gênero tendo em vista o funcionamento de práticas psiquiátricas que estabelecem o tão famigerado diagnóstico de transexualidade. 
Qual é a dinâmica de poder que se estabelece entre aquele sujeito transgênero que almeja o laudo por intermédio de um psiquiatra? A verdade do diagnóstico é estabelecida através de quais relações entre estes dois sujeitos, como e onde a verdade diagnóstica emerge? De que tipo é esta verdade, quais saberes e práticas médicas e psicológicas são acionadas na constituição desta verdade sobre o gênero e suas patologias?

Trata-se de observar através de quais jogos de verdade o sujeito se reconheceu enquanto portador de uma doença de gênero dentro deste dispositivo médico e quais as possíveis linhas de fuga a este imperativo da verdade sobre o gênero. Compreender como se dá a relação entre esta prática de reconhecimento de si tendo em vista o funcionamento de um poder psiquiátrico que estipula verdades sobre o diagnóstico de disforias de gênero.

Foucault (2006) concebe duas formas distintas de verdade: a verdade enquanto evidência ou acontecimento. A verdade enquanto evidência é aquela que "está em todo lugar e em todo tempo", é vinculada a certa posição filosófico-científica que coloca a aparição da verdade condicionada a uma tecnologia de construção da constatação. A verdade-evidência se põe passível de ser descoberta pressupondo a sua existência prévia e independente ao sujeito que viria conhecê-la; por outro lado, a verdade como acontecimento se dá como um relâmpago ou aparição, ela aponta para a questão da dispersão, da localidade, da contingência própria à verdade. Nessa concepção da verdade como acontecimento, a relação da verdade com o sujeito de conhecimento não é a mesma como ocorre com a verdade -evidência: há implicações distintas do sujeito com a verdade. Na verdade -acontecimento o sujeito não é prévio à descoberta da verdade, tampouco a verdade é prévia ao sujeito: o sujeito de conhecimento se transforma na medida em que conhece a verdade.

Se consideramos que a produção do laudo põe em jogo a busca da verdade de si mesmo, ou seja, trata-se de responder ao imperativo "qual é a sua verdadeira identidade? Qual é a sua verdadeira identidade de gênero? Qual é o seu diagnóstico preciso, verdadeiro?” a distinção entre verdade 
como evidência ou acontecimento é de suma importância para compreender o modo de funcionamento das práticas psiquiátricas e como o poder é exercido nestes espaços das clínicas.

Vamos nos perguntar: a verdade do gênero do indivíduo portador de uma disforia é da ordem da evidência ou do acontecimento? Questões que nos colocam igualmente outras questões: o próprio gênero enquanto objeto a ser conhecido se dá na ordem da apreensão enquanto evidência ou acontecimento? Conhecer seu próprio gênero implica em transformarse e romper com certa evidência subjetiva anterior ou voltar-se para e na fixidez identitária prévia de si?

Poderíamos ver o funcionamento tanto da verdade evidência quanto da verdade acontecimento operando nos discursos médicos sobre a transexualidade. Para Foucault, aliás, não se trata de opor a verdade-acontecimento e a verdade-evidência como sistemas completamente distintos de verdade. Tampouco a psiquiatria pôde se constituir como uma disciplina capaz de construir um saber que diria a verdade da doença mental enquanto mera constatação científica.

Ao contrário, a verdade-evidência, nas palavras do autor, recobriu, colonizou e parasitou a verdade-acontecimento. Com isso se quer dizer que a verdade-evidência, antes de dizer respeito à tão sonhada neutralidade ou objetividade científica, é igualmente produzida através de rituais específicos de poder, se assemelhando neste aspecto com a verdade-acontecimento. A verdade-evidência não seria produzida independentemente do poder, se trata, ao invés, de um certo funcionamento da modalidade de produção de conhecimento em que o poder se mostra como elidido ou dissimulado.

Diria então que há a prevalência no dispositivo da transexualidade, por mais que a psiquiatria não consiga expulsar para fora de seu campo científico a verdade enquanto acontecimento, da verdade do gênero como evidência. Primazia da fixidez em detrimento do descontínuo. Relações de poder entre estes dois sistemas de produção de verdades sobre as identidades de gênero, na tensão entre a constatação e o acontecimento. A psiquiatria não 
conseguiu de fato constatar a verdade da transexualidade inscrita no biológico; se trata, antes de tudo, de uma forma de funcionamento do poder psiquiátrico de dissimular o exercício de seu próprio poder neste domínio especifico que se refere aos transtornos de identidade de gênero.

Arrisco então dizer que a própria ideia de um laudo que ateste a patologia do gênero é profundamente estranha e incompatível à verdade enquanto acontecimento. Um laudo faz justamente isto: atesta uma verdade enquanto evidência científica, fazendo dizer a verdade do sujeito sem mesmo a necessidade do sujeito se implicar na produção desse conhecimento; isto porque a verdade construída pelo laudo é tautológica, ela cria e justifica a si mesma, a verdade do gênero se constitui exterior aos sujeitos, tanto às pessoas transgêneras que demandam terem seus gêneros discursivizados pelo e no diagnóstico quanto ao próprio psiquiatra que escreve o laudo, pois a verdade está no próprio diagnóstico.

Neste regime de verdade, o sujeito trans deve se manter o mais transparente possível entre a sua manifestação da verdade - inscrita na biologia - e sua decifração pelo psiquiatra a fim de se realizar um diagnóstico preciso. A posição do sujeito enquanto afirmada tenta ser anulada ao máximo neste processo, visto que o sujeito deve falar outra voz que a sua própria: uma voz capaz de fazer falar a própria biologia - a evidência científica tem que se mostrar enquanto tal, cristalina - de forma mais transparente possível para o psiquiatra.

Qualquer forma de tomada de posição enquanto sujeito, qualquer coisa que faça remeter ao sujeito será tido então pelo psiquiatra como um empecilho ao seu exercício de diagnóstico. Gênero é presumidamente inscrito na biologia, e para obter a verdade do gênero, é preciso estabelecer uma prática de interrogatório em que a biologia possa falar a disforia do corpo transexual de forma inequívoca.

A própria subjetividade é transformada em falsidade, um terrível véu que impede o acesso à verdade nesta discursividade que patologiza o gênero. Nessas relações, o psiquiatra poderá, em nome da verdade do gênero, 
excluir o sujeito do diagnóstico, imputando a curiosa denominação de "falso transexual".

Isso porque se o sujeito falar sobre seu gênero de outra forma, fugindo da racionalidade diagnóstica, estará sendo excluído deste regime de veridição das técnicas psiquiátricas. A subjetividade aparece como eterna possibilidade do sujeito enganar a si mesmo, pois o sujeito, ao assumir o que há de não todo e não contínuo no gênero na sua própria constituição subjetiva, estará fora dos regimes que produzem a verdade diagnóstica. É como se estivesse se autoiludindo. Se o sujeito não falar a partir das regras que permitem falar a biologia do corpo disfórico ele será tido então como um sujeito "iludido por si mesmo".

O poder psiquiátrico, desta forma, estabelece a própria distinção entre a realidade e a ficção, formas de subjetividade reais e outras ilusórias, distinção entre loucura e normalidade do gênero, tendo como base de sustentação de seu discurso a perspectiva biologista que afirma que há biologia no gênero, e a verdade do gênero é apreendida através da fala da biologia representada no diagnóstico.

A questão que aparece então não é acerca propriamente da verdade, mas do perigo que o sujeito de gênero tem em relação a si mesmo; a psiquiatria se põe então o papel de proteger os indivíduos de si mesmos. Aqui o perigo é do sujeito se reconhecer enquanto travesti, pois a travestilidade é o próprio perigo do gênero, ao fugir da nosologia transexual. Quero dizer: a travestilidade é perigosa na exata medida em que foge da verdade médica.

Se admitimos então que a verdade do gênero está no diagnóstico, qual é a verdade do diagnóstico? Quais práticas e saberes são mobilizados no diagnóstico de transexualidade verdadeira e da transexualidade falsa?

A verdade do diagnóstico se constrói sobretudo através da distinção entre realidade e ficção que me referi acima. Certamente a verdade do diagnóstico de disforia de gênero se mobiliza pelo conceito de transexualidade em detrimento da travestilidade. A travestilidade por vezes acaba sendo simbolizada como a falsa transexualidade pelo discurso psiquiátrico. 
A transexualidade é investida de sentido pelo discurso psiquiátrico e a travestilidade aparece como falta de sentido.

O sentido do gênero, no discurso psiquiátrico, envolve fortemente a construção de coerência de totalidade entre vários elementos que são passíveis de análise: diversos sentimentos, valorações, aparências, performances, desejos dispersos e contínuos dos sujeitos que são postos numa relação de sentido tendo em vista certa utilidade.

O sentido do gênero como "útil”, no diagnóstico, se baseia na coerência de certas normas sociais em relação ao gênero normal. A análise dessa coerência, contudo, não se dissocia das práticas de poder que fazem da cisgeneridade o destino natural dos sujeitos de gênero. A falsa transexualidade apareceria como quebra destas coerências, a falha de um sentido do sexo como um desdobramento óbvio que unisse a evidência da biologia e a evidência social da cisgeneridade.

A falha só se dá pela descontinuidade, por isso é importante acionar a verdade enquanto acontecimento para compreender a especificidade de formas de subjetivação que estabelecem linhas de fuga ao poder psiquiátrico.

O que proponho, frente a um posicionamento transfeminista, é contestar a verdade-diagnóstico que simboliza a travestilidade como falsa transexualidade. Para isso, vamos compreender a travestilidade não em sua negatividade abjeta e delirante, enquanto falta de uma coerência diagnóstica, mas como a própria verdade-acontecimento do gênero.

Eis o erro da psiquiatria: transformar o não todo, não coerente e não contínuo do gênero em falso. Cabe a nós a tarefa de apontar que gênero não é passível de ser posto sob escrutínio por meio de sistema de veridição; não se trata de fazer falar a verdade inscrita na biologia e distinguir então a falsa da verdadeira transexualidade, tampouco de fazer falar a biologia através de um regime de verdade que buscaria produzir a totalidade e coerência de uma disforia de gênero.

A biologia não pode falar, é preciso entender que a subjetivação em relação ao gênero não é a fala transparente da biologia, mas a fala de um 
sujeito de gênero. A biologia não fala, quem fala é o sujeito. $\mathrm{O}$ sujeito, em sua subjetividade, tem sua espessura própria. Não é passível de ser decifrado inequivocamente por um saber psiquiátrico.

A espessura do sujeito não ilude o psiquiatra e a própria pessoa de conhecer a identidade como um véu, ela não é empecilho para a verdade, ao contrário, é condição mesma de seu aparecimento.

O sujeito do gênero que conhece em si a verdade de seu próprio gênero, sob esta perspectiva, tampouco coincidirá consigo mesmo. Conhecer o próprio gênero implica o desconhecimento sucessivo de si resultando em uma destituição subjetiva - há ruptura em relação a si mesmo, pois o sujeito se encontra implicado na sua própria verdade enquanto acontecimento.

\section{Sobre vontades de saber}

Michel Foucault nos mostra que a vontade de conhecer algo não é inocente, tampouco neutra no que se refere às relações de poder. As relações entre o objeto de conhecimento e o sujeito de conhecimento não se dão de forma linear e sob a forma transparente de uma apreensão científica. Nosso objeto, a "identidade de gênero", esta coisa (?) a partir da qual eu suponho ter sido convidada hoje para discursar sobre, não nos permite reducionismos de ordens biológicas, sociológicas ou psicológicas.

Quero dizer, assumo de antemão que "identidade de gênero" não é um mero dado a ser apreendido a partir de conhecimentos que conjuguem a biologia, a sociologia e a psicologia. Não acredito que isto seja possível, pois parte integrante deste objeto a ser conhecido diz respeito à relação do sujeito consigo mesmo (subjetiva) e com outros (intersubjetiva).

Discursar aqui, a partir deste meu lugar, não é também uma tarefa cômoda. Quero dizer: é incomodo discursar sobre questões de identidade de gênero a partir de um lugar de palestrante a um público alvo que presumo estar sedento por conhecer este tema. A imagem que faço de vocês também inclui um sujeito de caráter aberto, minimamente "mente aberta", que de 
livre (e boa) vontade se dispõe a ouvir e aprender. De fato, não quero e não faço questão de pensar que eu esteja falando para bolsonaros ou malafaias!

Se estou presumindo que, a partir deste encontro, iremos poder construir conhecimento (de fato estou assumindo esta prerrogativa), temos que considerar também que a relação que estamos estabelecendo aqui não se resume absolutamente entre o sujeito de conhecimento e um determinado objeto.

Por diversas razões: primeiro que a relação que pretendo estabelecer com vocês se dá através da relação entre sujeitos (e não enquanto meros objetos a serem preenchidos pela minha fala) e o próprio objeto de nosso mútuo interesse - as identidades de gêneros - não se dissociam da própria categoria de sujeito. Temos então que considerar que a relação entre nós eu, Beatriz, que supostamente detenho o conhecimento, vocês plateia um tanto quanto uma massa inerte a "ser preenchida" de conhecimento acerca de nosso objeto de mútuo interesse - estabelecem relações extremamente complexas.

Por isso talvez seja necessário, antes de falar qualquer coisa em relação ao tema que me foi proposto, pensar acerca de certos imaginários que tomamos como dados que orientam os sentidos sobre uma palestra acerca dos lugares que ocupamos, eu enquanto palestrante, vocês enquanto público e, permeando nossas relações, esta presumida vontade de conhecer as "identidades de gênero".

Está presumido que eu, tendo a posse de determinado conhecimento, vou transmiti-lo a vocês, plateia. Eu vou suprir a falta de vocês, vou preencher vocês com informação que vocês muito provavelmente não sabem, vou educar vocês, lhes provir conhecimento e informações completamente inéditas. Aqui a educação por vezes aparece como acréscimo a partir de um espaço vazio - ocupado por vocês - que eu teria o papel de suprir. Nesta perspectiva, o público-ouvinte aparece demasiadamente objetificado assim como o próprio objeto de conhecimento a ser transmitido; temos então que nos atentar criticamente em relação a este imaginário. 
Igualmente não é indiferente o fato de eu ser uma pessoa trans e estar ocupando um espaço privilegiado na construção de conhecimento sobre o tema.

Com isso não estou dizendo que toda relação entre mestre-aluno, palestrante-ouvinte, professor-estudante tem que ser meramente abolida. De fato, para mim, enquanto pessoa trans, poder ocupar este espaço é algo absolutamente necessário e desejado por mim.

O que eu não posso deixar de passar batido, numa fala como essa em que toma este tema "identidade de gênero", é acerca desta vontade de verdade que subjaz todas as nossas posições e falas e que interfere de forma constitutiva no que estamos querendo conhecer.

A relação entre conhecimento e desconhecimento no nosso caso não se resume ao polo "vazio x cheio", "presente $\mathrm{x}$ ausente" ou "conteúdo x ausência de conteúdo". Diria que o desconhecimento acerca das identidades de gênero desviantes, as transgêneras, não se dá meramente pela ausência de determinado conteúdo ou informação; ao contrário, este tipo de desconhecimento se dá justamente pelo excesso de conteúdo e informação. O ódio transfóbico não se dá simplesmente porque falta informação; a transfobia, assim como todo ódio em relação a uma minoria, se dá porque algo foi preenchido excessivamente de sentidos. Sentidos de ódio no caso, mas poderiam ser sentidos de exotificação, colonização e condescendência igualmente.

Partimos de uma excessiva simbolização acerca das identidades de "homens" e "mulheres", todo mundo sabe o que é um gênero de verdade e o que é apenas uma "identidade". Diante de tamanho excesso, fica difícil simbolizar o recorte cis $\mathrm{x}$ trans. Vocês, então, ao invés de me pedirem que lhes diga algo de conteúdo acerca das identidades de gênero, deveriam me orientar muito mais para a deriva, a desconstrução e o questionamento deste excesso de conteúdo e informação que tomamos aprioristicamente acerca do gênero.

O que eu teria então para fornecer a vocês de conhecimento acerca das identidades de gênero? Se vocês esperavam que eu dissecasse as ínfimas 
diferenças e nuances que distinguem travestis, transexuais, transgêneros, cross-dressers, drag-queens e demais outras identidades possíveis e imagináveis, eu sinto em lhes dizer que esta não é minha intenção.

Vamos desconfiar por um momento da máquina de categorizar, levando em consideração que é justamente a excessiva produção de verdades acerca de determinadas categorias que funcionam na exclusão e no desconhecimento que me referi acima. Espero apontar para a possibilidade da deriva, da polissemia, da abertura de sentidos como forma ética de se relacionar com o que está excluído das formas de representação.

E aqui se trata sobretudo de uma educação ao diferente, ao oprimido e ao estigmatizado: o que eu faço com uma travesti, como devo tratá-la, o que devemos conhecer da travestilidade para ser educado(a) com ela, para ser respeitoso(a) com ela, para ser útil em relação aos seus problemas? $\mathrm{O}$ que eu, enquanto acadêmico - vejam só, estou me pegando na equivocidade de presumir um sujeito acadêmico cisgênero - devo saber do tema "identidade de gênero" para que meu conhecimento acadêmico - seja nas áreas médicas, de saúde mental, social - seja útil para esta população marginalizada?

Sem dúvidas existem diversas injunções aqui e elas são absolutamente necessárias. É absolutamente necessário, frente a uma realidade de inúmeras precaridades em relação a serviços básicos de saúde e de extrema exploração econômica e espiritual, os acadêmicos, em suas especialidades de saber, começarem a se posicionarem eticamente diante da realidade dos oprimidos: aqui das travestis, em especial. É preciso que diversos profissionais se interroguem em suas áreas de atuação frente a realidade das travestis: em que medida vocês enquanto classe profissional ou enquanto pessoas que não sofrem das injunções materiais deste grupo oprimido são responsáveis pela perpetuação ou mudança desta realidade? E trata-se também de um questionamento necessário inclusive para mim.

O que os psiquiatras e psicólogos tem a dizer frente a patologização das identidades trans? $\mathrm{O}$ que estes profissionais tem a dizer frente ao poder que lhes são concedidos a legitimarem os gêneros das pessoas trans 
em laudos - o que inclui dar o direito à própria vida? O que vocês, profissionais, têm a dizer do seu próprio poder?

Como eu disse, estabelecer critérios normativos em relação a um laudo de transexualidade é ter o poder de legislar sobre a vida e a morte, já que é a própria vida das pessoas transgêneras que estão a mercê deste controle: seus corpos, suas subjetividades, identidades, enfim, a própria vida é tomada enquanto passível de ser conhecida - leia-se controlada, exercida poder - por meio de um laudo de transexualidade. Legislar também sobre a própria verdade do gênero.

Um laudo tem o poder de traçar destinos na vida de uma pessoa trans. Diante disso, como pode a psiquiatria e psicologia se posicionarem frente a este poder? Pode o poder psiquiátrico e psicológico se mostrar tão elidido a ponto de práticas como a confecção de um laudo passarem a ser vistas como mera constatação de uma verdade científica extraída de um corpo disfórico e inerte?

Neste aspecto, é de suma importância que estes saberes psi problematizem a relação entre sujeito, objeto e conhecimento, o que significa questionar o próprio estatuto da verdade da identidade de gênero que é formulada em um diagnóstico: a relação, enfim, que se estabelece entre dois sujeitos que ocupam espaços distintos (enquanto transgênero e profissional psi) e o objeto a ser conhecido, o próprio gênero do sujeito trans. Este objeto a ser conhecido não é apreendido como mera constatação de um fato que é extraído de um substrato biológico, psicológico ou sociológico, mas é estabelecido através da relação do sujeito consigo mesmo na relação com este profissional psi. Para compreender o funcionamento destes saberes psi temos que nos atentar para relações complexas que se dão de forma inter e intrasubjetivas, perpassadas pelas instituições.

Para compreender então a dinâmica destas relações é preciso, sobretudo, levar em consideração o que é externo a estes saberes tipicamente psíquicos. Quero dizer, em que medida certas injunções jurídicas, burocráticas, sociais e econômicas (enfim, tudo ligado a uma forma de instituição que vá além da clínica) exercem influencia na relação entre profissional psi 
e pessoa trans acerca da construção deste complexo objeto a ser conhecido a partir de si mesmo na mediação com um profissional, sua "identidade de gênero" ou seu "diagnostico".

Partimos de uma realidade em que diversas instâncias exigem o laudo de transexualidade para acessarmos direitos básicos, como mudança de nome nos documentos oficiais, acesso à saúde e validação em diversas esferas sociais que exigem a comprovação que de fato o sujeito em questão tenha um diagnóstico preciso de transexualidade.

Diante deste cenário, não há como afirmar que as pessoas não estejam a priori coagidas por diversas forças a terem seus gêneros legitimados por este saber psicológico e psiquiátrico. $\mathrm{O}$ que as disciplinas como psicologia e psiquiatria têm a fazer não é denegar estas injunções de força, não é encenar uma consulta-diagnóstica que supostamente estaria livre destas terríveis coerções do poder. É preciso que a psiquiatria e psicologia tenham um olhar mais honesto e ético em relação a suas próprias práticas, ao compreender o complexo funcionamento do poder que envolve a formulação de um laudo de transexualidade.

"Descobrir", "conhecer", "atestar" a inconformidade de gênero em um diagnóstico de transexualidade não é a construção de uma constatação neutra. Colocar a transexualidade como verdade a ser descoberta e extraída nos recônditos dos corpos disfóricos, tampouco.

Falamos acerca da despatologização da transgeneridade. Minha intuição me dizia há tempos que este debate tem muito mais a ver com o modo do funcionamento das práticas e saberes psiquiátricos do que meramente a presença e ausência de uma categoria na Classificação Internacional das Doenças (CID) ou no Manual Diagnóstico e Estatístico de Transtornos Mentais (DSM).

Enquanto a psiquiatria e a psicologia não compreenderem o laudo enquanto mero instrumento a ser utilizado pelas pessoas trans, se assim o quiserem, como estratégia de resistência frente a uma realidade precária, não estaremos avançando dentro da psicologia e psiquiatria. $O$ laudo deve proporcionar agência às pessoas transgêneras, e não o contrário, como 
vem representando até agora: medo e apreensão de se encaixar corretamente.

O laudo deve ser esvaziado do seu conteúdo de verdade enquanto constatação de uma doença e ser visto como um instrumento biopolítico. Esse instrumento biopolítico deve estar à disposição daquele sujeito que o laudo atesta. O laudo não deve ser compreendido como resultado de uma tecnologia precisa de veridição e subsequente exclusão entre quem é transexual verdadeiro e de quem é transexual falso.

O laudo deve ser compreendido fora deste sistema de veridição que coloca todo momento sob suspeita a identidade do sujeito; ele não deve ser resultado de uma tecnologia de desvelamento e construção de evidência, mas sim enquanto instrumento a servir ao reconhecimento da autoidentificação de um sujeito.

Laudo enquanto estratégia do poder frente a uma realidade precária se opondo ao laudo enquanto constatação: desta forma vislumbro a possibilidade da psiquiatria e psicologia de estabelecerem uma relação de autocrítica acerca de seus próprios saberes-poderes-verdades.

É nesta direção que penso que temos que seguir quando falamos da discussão, em nossa realidade brasileira, acerca da despatologização da transexualidade. A despatologização não significa, como costumam pejorativamente acusar, falta de acesso a terapias psicológicas ou falta de atendimento à saúde; também não significa a mera exclusão de categorias em manuais diagnósticos.

A despatologização significa a mudança e autocrítica, dentro dos espaços e discursos das clínicas, dos saberes e práticas dos psiquiatras e psicólogos tendo em vista um deslocamento da forma como se encara a relação dos sujeitos com suas identidades de gênero: se deslocando do modelo biomédico de constatação de evidências pretensamente científicas para um modelo ético e politicamente engajado. 


\section{Referências}

FOUCAULT, M. Aula de 23 de janeiro de 1974. In: FOUCAULT, M. O poder psiquiátrico: curso dado no Collège de France (1973-1974). São Paulo: Martins Fontes. 2006

$\frac{248}{\operatorname{cop}}$ 